\title{
Unawareness for motor impairment and distorted perception of task difficulty
}

\author{
Gianna Cocchini ${ }^{1,2}$, Nicoletta Beschin ${ }^{3}$, and Sergio Della Sala ${ }^{4}$
}

${ }^{1}$ Department of Psychology, Goldsmiths University of London, UK

${ }^{2}$ Blackheath Brain Injury Rehabilitation Centre and Neurodisability Service, London, UK

${ }^{3}$ Clinical Neuropsychology Unit, Rehabilitation Department, Hospital S. Antonio Abate, Gallarate (Varese), Italy

${ }^{4}$ Human Cognitive Neuroscience, Psychology, University of Edinburgh, Edinburgh, UK

Address correspondence to:

Gianna Cocchini

Psychology Department

Goldsmiths University of London

New Cross

London SE14 6NW

U.K.

Email: g.cocchini@gold.ac.uk

Words: 4881 (references and abstract excluded) 
Cocchini et al. Unawareness and distorted perception of task difficulty

\section{ABSTRACT}

Objective: Anosognosia for motor impairment is a complex syndrome that can manifest itself under different forms, guiding patients' behaviour and task decisions. However, current diagnostic tools tend to evaluate only more explicit aspects of anosognosia (asking the patients about their motor abilities) and fail to address more subtle features of awareness. We have developed a new assessment measure, the ECT (Errand Choice Test), where patients are asked to judge task difficulty rather than estimate their own impairment. Method: We assessed awareness in a group of 73 unilateral left- and right-brain damaged (30 LBD and 43 RBD, respectively) patients by means of the VATAm, which explicitly requires them to evaluate their own motor abilities, and the ECT. A control group of 65 healthy volunteers was asked to perform the ECT under two conditions: Current condition (i.e. using both hands) and Simulated conditions (i.e. simulating hemiplegia). Results: $27 \%$ of the patients showed different performance on the VATAm and ECT, $21 \%$ of the patients showing lack of awareness only on VATAm and 6\% only on ECT. Moreover, despite the ECT identified a higher frequency of anosognosia after RBD (33.3\%) than LBD (27.6\%), this hemispheric asymmetry was not significant. Remarkably, anosognosic patients performed very similarly to controls in the 'current condition', suggesting that anosognosic patients' ability to perceive the complexity of each task per se is not altered. Conclusion: Different methods may be able to tackle different aspects of awareness and the ECT proved to be able to detect less evident forms of awareness.

Keywords: anosognosia, unawareness, hemiplegia, assessment, brain damage, implicit. 
Cocchini et al. Unawareness and distorted perception of task difficulty

\section{INTRODUCTION}

Anosognosia for hemiplegia is usually assessed asking the patients about their motor abilities (Marková \& Berrios, 2014). Patients may be asked to respond to structured interviews investigating their ability to move their limbs (Jenkinson, Preston, \& Ellis, 2011; Nurmi \& Jehkonen, 2014 - see also Table 1) or to rate their motor performances in everyday tasks (e.g., Marcel, Tegnér, \& Nimmo-Smith, 2004; Della Sala, Cocchini, Beschin, \& Cameron, 2009, Prigatano, 2014 - see also Table 1). Invariably, these evaluations imply some degree of metacognition: patients are asked to estimate their own motor skills and, in some cases, they are asked to comment on their previous performance and use of strategies (Moro, Scandola, Bulgarelli, Avesani, \& Fotopoulou, 2015). However, there is evidence to suggest that lack of explicit awareness may be associated to some degree of insight (e.g., Marcel et al., 2004; House \& Houdges, 1988; Nardone, Ward, Fotopoulou, \& Turnbull, 2007; Cocchini, Beschin, Fotopoulou, \& Della Sala, 2010; Fotopoulou, Pernigo, Maeda, Rudd, \& Kopelman, 2010; Prigatano, 2014; D’Imperio, Bulgarelli, Bertognoli, Avesani, \& Moro, 2017). Patients may verbally deny their motor deficits yet abstain from activities requiring the use of both hands (Bisiach \& Geminiani, 1991) or adopt successful strategies in approaching bi-manual tasks using one hand (Cocchini et al., 2010; Moro, Pernigo, Zapparoli, Cordioli, \& Aglioti, 2011; Garbarini, Piedimonte, Dotta, Pia \& Berti, 2013) or refrain to perform potentially dangerous activities for hemiplegic patients (D’Imperio et al., 2017). In contrast, Ramachandran (1995) reported on anosognosic patients who consistently chose bi-manual rather than uni-manual tasks concluding that they did not show a 'tacit knowledge' of their paralysis.

Brain damaged patients can suffer from different degrees of motor deficits, and those with moderate or mild motor impairment may also show anosognosia. However, in order to accurately interpret "responses to specific questions, such as - Can you move your hand? [...], the criterion of complete paralysis [is] necessary" (Nathanson, Bergman, \& Gordon, 1952, 
Cocchini et al. Unawareness and distorted perception of task difficulty

p. 381). This leads to the exclusion from the assessment of patients showing moderate and mild forms of motor impairment. Furthermore, the exclusion from assessment of several left-brain damaged patients may be due to associated language difficulties. Therefore, the assessment of anosognosia for right and left-brain damaged patients not showing severe hemiplegia ought to rely on different methods enabling the examiner to reliably interpret the patients' responses according to their degree of motor impairment.

Inspired by a previous study by Ramachandran (1995), this study aims at devising a novel method to investigate less explicit aspects of anosognosia by asking patients to judge the difficulty of several motor tasks, rather than estimate their own motor disability. This instrument, labelled Errand Choice Task, allowed us to assess patients with different degrees of motor impairment as well as left-brain damaged patients showing with language deficits.

\section{--- Insert Table 1 about here ---}

\section{METHOD AND MATERIALS}

\section{Participants}

A total of 138 participants were recruited for this study. None had any previous history of psychiatric disorders. The study was completed in accordance with the Helsinki Declaration and all participants gave informed consent.

\section{$\underline{\text { Patient group }}$}

A group of 73 (33 women) brain damaged patients recruited in the Brain Injury Rehabilitation Unit, Somma Lombardo Hospital (Italy) entered the study ${ }^{1}$. Their demographic and clinical 
Cocchini et al. Unawareness and distorted perception of task difficulty

data are detailed in Table 2. They all suffered from a first stroke; 30 had unilateral left hemisphere damage (LBD) and 43 had unilateral right hemisphere damage (RBD). Clinical neuroimaging (CT/MRI scans) showed that most patients $(n=56)$ had a lesion encompassing, or limited to, the frontal and parietal lobes. Compared to RBD, the LBD patients had on average a longer onset-assessment interval; this difference fell short of significance ( $\mathrm{t}$-crit=1.882; $\mathrm{p}=.064)$.

To be considered for the experiment, patients had to present with clear contralesional motor impairment in their upper limb, as assessed by means of the Motricity Index (Wade, 1992). During this assessment, the patient sat on a chair or a wheelchair; three left/right upper limb movements were assessed: "pinch grip", "elbow flexion" and "shoulder abduction". For each of these movements, a score from 0 (no movement) to 33 (normal power) is given. The score for upper limb movements is then calculated by adding the score for the three movements plus 1, to give a total score between 1 (severe motor impairment) and 100 (no motor impairment). Poor performance due to apraxia, tremor or ataxia is not considered as evidence of paresis. As reported in Table 2, the scores indicate that the patients presented with various degrees of motor impairment, with 43 out of 73 patients showing complete paresis in their upper limb

Patients' independence in performing daily tasks (such as mobility, bathing, dressing) was evaluated by means of an ADL scale (Activity of Daily Life; Katz, Ford, Moskowitz, Jackon, \& Jaffe, 1963; Mahoney \& Barthel, 1965) where lower scores indicate lower degrees of independence. As reported in Table 2, the patients obtained on average a score of 8.5 out of 20, indicating an important decline of everyday independence. A series of t-test analyses was conducted to compare demographical (age, education level) and clinical (onset from lesion, motor impairment for upper limb and ADL score) variables between LBD and RBD. No significant differences were found. 
Cocchini et al. Unawareness and distorted perception of task difficulty

--- Insert Table 2 about here ---

Patients were also assessed with a comprehensive neuropsychological battery. Extrapersonal neglect was assessed by means of two cancellation tasks (Line cancellation Albert, 1973 and Star cancellation - Wilson, Cockburn, \& Halligan, 1987) and by means of a Line Bisection Test (Wilson et al., 1987). Personal neglect was assessed by means of the Fluff Test (Cocchini, Beschin, \& Jehkonen, 2001), the Comb/Razor Test (Beschin \& Robertson, 1997) and the One Item Test (Bisiach, Perani, Vallar, \& Berti, 1986). Reasoning abilities were assessed by means of the Vertical version of the Raven Progressive Matrices (Gainotti, D’Erme, Villa, \& Caltagirone, 1986; norms in Spinnler \& Tognoni, 1987). Non-verbal shortterm memory was measured with the Corsi Blocks test (Spinnler \& Tognoni, 1987). Table 3 reports percentage of patients showing pathological performance on these tests.

--- Insert Table 3 about here ---

\section{Control group}

A group of 65 (42 women) right-handed, healthy volunteers entered the study to refine the items and the scoring system of the Errand Choice Test (see below). Their mean age was 44.4 $(\mathrm{sd}=21.0 ;$ range $=17-82)$ and they had a mean of 11.7 years of formal education $(\mathrm{sd}=4.7$; range $=3-20)$. Controls' age was significantly lower than LBD ( $\mathrm{t}$-crit $=4.5 ; \mathrm{p}<.01)$ and RBD $(\mathrm{t}$-crit=4.9; $\mathrm{p}<.01)$, whereas education level was not significantly different between controls and both patient groups. 
Cocchini et al. Unawareness and distorted perception of task difficulty

\section{Assessment Procedures}

$\underline{\text { Anosognosia assessment }}$

Visual-Analogue Test for Anosognosia for Motor Impairment (VATAm).

To assess evidence of anosognosia for upper limb motor deficits, all brain damaged patients underwent the VATAm (Della Sala et al., 2009). In this test, patients are requested to rate (from $0=$ no problem to $3=$ severe problem), one at a time, their ability to perform a series of simple everyday motor tasks, such as clapping their hands. For the purpose of this study only the subscale for the upper limb, which consists of 8 bi-manual tasks, was considered (score range: 024). There were also 4 check questions, for which the expected ratings lay at one or the other extreme of the scale. Performance on the check questions was not added to the score, as they were used solely to ensure the participants' compliance and reliability. The patients' selfevaluation was compared with the ratings of their caregivers who filled in the questionnaire evaluating the patient's motor skills. The resulting score, i.e. the caregiver-patient discrepancy value, obtained by subtracting the patient's self-rating of the 8 bi-manual tasks from those given to the patient by their caregivers, could be checked against available norms (Della Sala et al., 2009). This score indicates the patient's degree of awareness/unawareness for their upper limb motor impairment. In the VATAm, the possible discrepancy value for upper limb items ranges from -24 (negative values indicate patient's overestimation of their motor deficit compared to the caregiver's judgment) to +24 (positive values indicate patient's underestimation of their motor deficit compared to the caregiver's judgment, i.e. unawareness of their own deficits). According to the norms set in Della Sala et al. (2009), values falling between 3.8 and 8.0, 8.1 and 16.0 or 16.1 and 24.0 were taken to indicate mild, moderate or severe anosognosia, respectively. 
Cocchini et al. Unawareness and distorted perception of task difficulty

\section{Errand Choice Test (ECT)}

A novel task was devised for the purpose of this study: The Errand Choice Test. To assess the perception of one's own motor skills and its implication on task choice, participants were presented with a list of 18 pairs of everyday tasks. Each pair consisted of one task usually performed with one hand (uni-manual task - e.g., 'Comb your hair') and one task usually performed with both hands (bi-manual task - e.g., 'Fold a sheet in half'). Each task was illustrated by a drawing to clarify the type of performance requested and to emphasise whether the tasks required the use of either only one or both upper limbs (see Figure 1a for an example). For each pair, participants had to decide which task they would find it easier to perform in their current condition.

--- Insert Figure 1 about here ---

Material and procedure for this test were refined by means of three pilot studies with small groups of healthy volunteers and brain damaged patients (not included in the final sample groups). The three phases of the pilot studies allowed us to i) (phase 1) classify each task as either uni-manual (i.e., a task usually performed with one hand) or bi-manual (i.e., a task usually performed using two hands); ii) (phase 2) create unambiguous illustrations of each task to facilitate comprehension, minimize memory load and underline the use of one or two hands; and iii) (phase 3) select the tasks less sensitive to age or gender.

In the final version of the Errand Choice Test, drawings for each pair of tasks were presented on an A4 sheet on the ipsi-lesional side of the testing desk, the question they depicted was also read aloud by the experimenter while pointing to the corresponding drawing. Sixteen pairs (each consisting of one uni-manual and one bi-manual task) constituted the experimental trials. In half of the trials the uni-manual task was presented first and to the left side of the A4. Two 
check items were also used. Based on pilot data, in each pair of the check items, one of two tasks was clearly much easier to be performed than the other one (i.e. 'Drink from a glass' easy task; 'Rip a bush with roots' - difficult task) even with no motor impairment (see Figure $1 \mathrm{~b}$ for examples). If participants did not provide the expected response on these check questions, their data were excluded from further analyses.

The eighteen pairs (16 experimental trials and 2 check pairs) were presented in a fixed pseudo-random order with the two check questions as first and last items (core actions for each pair are listed in Table 4). For each item in the pairs, participants were invited to evaluate the difficulty of the tasks and then indicate which of the two tasks they would consider easier to perform in their current situation (Current condition). There was no time limit for responses and questions could be repeated if required. The scoring system is detailed in the Result section.

To assess the reliability of the Errand Choice Test, 28 patients were asked to perform it again on Current condition between 1 and 3 days later.

Brain damaged patients performed the VATAm and ECT in random order.

In addition, the controls were presented a second time with the same pair of tasks but, on this occasion, they were asked to re-evaluate the task difficulty indicating which task they would consider easier to perform should they not be able to move one of their arms (Simulated condition).

\section{Statistical analyses.}

As in in previous studies (e.g., Cocchini et al., 2009), a t-test for single cases by Crawford and Garthwaite (2007) was used to established cut-off scores of the new ECT. ANOVA and t-test analyses for independent groups have been used to compare hemispheric differences and different awareness degrees. In case of multiple comparisons, we adopted Bonferroni 
correction. Finally, non-parametric Spearman correlations have been run to analyze reliability of ECT and its relationship with others variables.

\section{RESULTS}

\section{VATAm (upper limb sub-scale)}

Fourteen out of 30 LBD patients $(46.6 \%)$ showed evidence of severe ( 7 cases), moderate (5 cases) or mild (2 cases) explicit anosognosia. Twenty-one out of the 43 RBD patients (48.8\%) showed evidence of severe ( 8 cases), moderate ( 7 cases) or mild (6 cases) explicit anosognosia. Averaged discrepancy scores for aware and unaware LBD and RBD patients are shown in Table 5. The differences between aware and unaware LBD and RBD patients were not reliable $(\mathrm{t}-\mathrm{crit}=-1.169 ; \mathrm{p}=\mathrm{ns} ; \mathrm{t}-\mathrm{crit}=.635 ; \mathrm{p}=\mathrm{ns}$, respectively).

\section{Errand Choice Test}

\section{$\underline{\text { Controls }}$}

One healthy volunteer was excluded as he interrupted the test. Therefore, analyses were carried out on 64 healthy volunteers' responses and their performance on the two conditions. Table 4 illustrates the scores on Current and Simulated conditions. Scores in both conditions poorly correlated with age $(\mathrm{r}=.066 ; \mathrm{p}=.602$ and $\mathrm{r}=-.134 ; \mathrm{p}=.291$, current and simulated condition, respectively). In all pairs, uni-manual choices increased under Simulated condition. The difference between the two conditions represented the "awareness" factor. In other words, the proportion of controls who identified the uni-manual task as easier only when they simulated hemiplegia represented the 'pure' impact of being aware of not being able to move one arm. 
This difference (i.e., Simulated minus Current) for each pair of items was then considered to assign a weighted score for each choice and develop a weighted scoring system (See Table 4). In order to establish a cut-off value and interpret each individual patients' performance, controls' performance during the Simulated condition was then recalculated assigning the related weighted score of each pair when the uni-manual task was chosen. The overall weighted score could range from 0 (if no uni-manual task was chosen) to 405 (if all uni-manual tasks were chosen). On average, healthy volunteers under Simulated condition obtained a weighted score of $389.25(\mathrm{sd}=29.35$; range $=289-405)$.

Crawford \& Garthwaite's (2007) t-test was used to establish the lowest value (weighted score) below which performance should be considered abnormal. An overall weighted score lower than 318 (out of 405) was significant with $\mathrm{p}<.01$ and it was then set as cut-off point to interpret the patients' performance.

--- Insert Table 4 about here ---

\section{$\underline{\text { Patients }}$}

One LBD patient (case 57) and one RBD patient (case 20) were excluded from further analyses as they failed at least one check question. Therefore, further analyses were run on a sample of 29 LBD and 42 RBD patients. Each patient was assigned a weighted score every time the unimanual task was chosen as easier. For example, had a patient chosen as easier tasks 'Fingers through hairs' in the first pair, 'Prune a small plant' in the fourth pair and 'Pick up a card' in the last pair, this patient's ECT score would have been 64 (i.e. $25+25+14$; See Table 4 for weighted scores for each pair). Looking at individual scores, 22 patients ( 8 - 27.6\% LBD patients, and $14-33.3 \%$ RBD patients) performed below cut-off on the Errand Choice Test showing evidence of lack of awareness in estimating task difficulty given their motor 
Cocchini et al. Unawareness and distorted perception of task difficulty

impairment (see Figures 2 and 3). Six of the 8 anosognosic LBD patients and 7 of the 14 anosognosic RBD patients had complete paresis. Errand Choice Test scores for aware and unaware LBD and RBD patients are shown in Table 5. The overall difference between LBD and RBD patients' scores was not significant $(\mathrm{t}-\mathrm{crit}=.693 ; \mathrm{p}=\mathrm{ns})$. Considering aware and unaware patients separately, the ECT differences between LBD and RBD patients were also not significant $(\mathrm{t}-\mathrm{crit}=-1.507 ; \mathrm{p}=\mathrm{ns} ; \mathrm{t}-\mathrm{crit}=-.865 ; \mathrm{p}=\mathrm{ns}$. , for aware and unaware patients, respectively).

The 28 (10 LBD and 18 RBD) patients who performed the Errand Choice Test twice obtained an average score of $307.79(\mathrm{sd}=111.53)$ on first testing and an average re-test score of $298.54(\mathrm{sd}=122.02)$. The difference was not significant $\left(\mathrm{t} \_\right.$crit= $\left..965 ; \mathrm{p}=\mathrm{ns}\right)$. A Spearman correlation run between the test and the re-test scores indicated a high positive correlation $(\mathrm{r}=$ $.91 ; \mathrm{p}<.001)$.

--- Insert Table 5 and Figures $2 \& 3$ about here ---

Finally, we calculated a weighted score on Current condition (i.e., when they were free to think that they could use both hands) for each of the 64 controls, following the same scoring procedure used with the patients. We then compared the performance of the Controls with those the 49 aware patients and the 22 anosognosic patients. Not surprisingly, patients aware of their motor deficit scored very high $($ mean $=387.1 ; \mathrm{sd}=22.8)$ on the Errand Choice Test, indicating that they considered the uni-manual tasks easier than the bi-manual tasks. Anosognosic patients and controls obtained similar scores (anosognosic patients' mean=235.8; $\mathrm{sd}=63.9$; controls' mean $=241.0 ; \mathrm{sd}=64.01$ ), indicating that anosognosic patients' rating was led by the incorrect assumption they could use both hands. A 2 (LBD, RBD) x 2 (aware, unaware) ANOVA showed a significant effect of awareness $(\mathrm{F}(1,67=217.02 ; \mathrm{p}<.001)$ but no other interactions. Two 
Cocchini et al. Unawareness and distorted perception of task difficulty

further t-test analyses between controls and both aware and unaware patients showed a significant difference only between controls and aware patients $(\mathrm{t}$-crit $=15.22 ; \mathrm{p}<.001)$.

\section{Comparing performance Errand Choice Test and VATAm}

Two patients were excluded from the Errand Choice Test analyses (see above). Therefore, results from 71 patients (29 LBD and 42 RBD) on the VATAm and Errand Choice Test were compared. As shown in Table 6, 37 (52.1\%) patients showed evidence of unawareness on at least one test, $25.3 \%$ of them showed lack of awareness on both tests, and VATAm identified $15 \%$ more patients as anosognosics than the Errand Choice Test.

A non-parametric Spearman correlation run with all 71 patients between Errand Choice Test scores and VATAm discrepancy scores resulted in a negative significant correlation $(\mathrm{r}=-.48 ; \mathrm{p}<.001)$, indicating that those patients who were less aware on the VATAm were also less aware on difficulty of bimanual tasks.

--- Insert Table 6 about here ---

\section{DISCUSSION}

Often, the behaviour of patients is not consistent with their explicit acknowledgement/denial of their motor deficit (e.g., Ramachandran \& Blakeslee, 1998; Cocchini et al., 2010; Moro et al., 2011). Some studies have shown that patients may indirectly acknowledge hemiplegia when it is attributed to another person (e.g., Marcel et al., 2004). It follows that anosognosia for one's own motor deficits manifests at different degrees of awareness (e.g., Marcel et al., 2004; see Heilman, 2014 for a recent review) and methods to assess anosognosia should reflect such complexity (Jenkinson et al., 2011). By means of a newly devised test (the Errand Choice Test), we investigated less evident aspects of awareness for different degrees of severity of 
motor impairment in a sample of 73 brain damaged patients who were asked to judge task complexity rather than focus on their own deficit. On this test, they had to identify which of the two possible motor tasks (one uni-manual and one bi-manual) would be easier to perform in their current condition. Poor comprehension or general poor compliance were addressed using check items whereby participants were asked to identify the easiest task between two uni-manual tasks of clearly different difficulty. Our sample showed a relatively low exclusion rate as only two participants did not provide the expected responses and their results had to be excluded from the analyses.

The Errand Choice Test proved to be reliable showing a very high test re-test correlation, suggesting that the task is relatively sheltered by fluctuations of possible confounding variables, such as attentional disorders, perseveration, general lack of compliance and practice effect. Moreover, despite reduced risky decision-making has been associated with ageing (e.g., Di Rosa et al., 2017), the ECT performance seems unrelated by age. This may be due to the low complexity of the decision task required in this test, which is therefore suitable for different ages.

A sample of 65 healthy volunteers performed the test under two different conditions. Data collected under 'Current' (i.e. being able to use both upper limbs) and 'Simulated' (i.e., pretending to be unable to use one arm) conditions allowed us to identify the actual impact of awareness for possible motor impairment on each item. Comparison of data from these two conditions enabled us to establish whether the choice of uni-manual task mainly depends on general perception of ease or on awareness that one arm could not be moved (Simulated condition). For example, in the Current condition $53 \%$ of the controls considered the unimanual task "Scratching your nose" easier than the bi-manual task "Clapping your hands". However, in the Simulated condition the choice of the uni-manual task rose to $98 \%$, suggesting that the increased percentage (i.e., from $53 \%$ to $98 \%$ ) of uni-manual choices was mainly driven 
Cocchini et al. Unawareness and distorted perception of task difficulty

by the "awareness" of not being able to move one arm. This information was then implemented to develop a weighted scoring system to interpret clinical data in terms of normal/pathological performance. To minimize the risk of false positives, we calculated a conservative cut-off (i.e., 318 with $\mathrm{p}<.01$; which corresponds to a value nearly 3 standard deviations from the norms' mean). Considering this cut-off, we identified a sizeable group of $31 \%$ (i.e., 22/71) brain damaged patients showing distorted perception of task difficulty. These patients may engage in motor activities without adopting correct strategies to compensate for their motor impairment, increasing their chance to employ risky behaviours. It should be noted that 9 out of 22 anosognosic patients did not have complete hemiplegia of their upper limb. As suggested by Nathanson et al. (1952), also non-paretic patients may show considerable lack of awareness for their motor deficits and these may have passed unnoticed due to methodological shortcomings. This may explain why patients showing hemiplegia may need longer assistance after discharge from rehabilitation, as some of them may be unable to adopt safety measures (Hartman, Soroker, \& Katz, 2001).

Another significant outcome of the present study is the weak hemispheric asymmetry of anosognosia. Despite unawareness was numerically more frequent and on average more severe amongst RBD patients than LBD patients, the difference between the two groups was not significant, suggesting that lack of awareness for right hemiplegia may not be a negligible factor. While there is a general agreement on the association between anosognosia and righthemisphere damage (for recent reviews see Pia, Neppi-Modona, Ricci, \& Berti, 2004; Orfei et al., 2007; Heilman, 2014; Nurmi \& Jehkonen, 2014; see also Table 1), the relationship between awareness and left hemisphere is more debatable (Morin, 2007; 2017). Investigations of anosognosia for hemiplegia following damages of the dominant hemisphere are scant (see e.g., Nurmi \& Jehkonen, 2014 Table 4) and some authors consider anosognosia for right hemiplegia a rare occurrence that can be observed only in very specific circumstances (e.g., Baier et al., 
Cocchini et al. Unawareness and distorted perception of task difficulty

2014). However, recent studies have reported a less sporadic occurrence of anosognosia following damage of the left hemisphere (Hibbard, Stein, Gordon, \& Sliwinski, 1992; Grotta \& Bratina, 1995; Hartman-Maier et al., 2001; Hartman-Maier, Soroker, Ring, \& Katz, 2002; Hartman-Maier, Soroker, Oman, \& Katz, 2003; Appelros, Karlsson, Seiger, \& Nydevik, 2007; Cocchini, Beschin, Cameron, Fotopoulou, \& Della Sala, 2009). For example, Hartman-Maier and colleagues (2003) reported that anosognosia at admission was present in 53\% of right- and up to $41 \%$ of left-brain damaged patients. The authors reported similar pattern of results in chronic phases where anosognosia was observed on $27 \%$ right- and $23 \%$ left-brain damaged patients. Appelros et al. (2007) examined anosognosia in a large sample of brain damaged patients and reported non-significant hemispheric difference for anosognosia with 'only' 54\% of the 46 anosognosic patients suffering right-brain lesion. It is possible that presence and frequency of anosognosia following LBD may be inflated to an inability to recognise or represent the correct action (Pazzaglia, Pizzamiglio, Pes, \& Aglioti, 2008). However, in our final analyses we only considered patients who provided correct responses to all the check questions, suggesting that these patients had an appropriate understanding of the task and were able to correctly recognise the target actions.

Outcomes from studies with intra-carotid sodium amobarbital procedure (Wada Test) are also far from conclusive about the relationship between left hemisphere and awareness. Nearly all of these studies showed a higher frequency of anosognosia for left hemiplegia, which ranged between 66\% (Dywan, McGlone, \& Fox, 1995) to 100\% (Gilmore, Heilman, Schmidt, Fennell, \& Quisling, 1995); however in these same studies the frequency of anosognosia for right hemiplegia ranged from 0\% to 86\% (Gilmore et al., 1995; Carpenter et al., 1995; Buchtel, Henry, \& Abpu-Khalil, 1992; Kaplan, Meadows, Cohen, Bromfield, \& Ehrenberg, 1993; Dywan et al., 1995; Durkin, Meador, Nichols, Lee, \& Loring, 1995; Lu et al., 1997) and the difference between the two hemisphere conditions could also range from 0\% (Dywan et al., 
Cocchini et al. Unawareness and distorted perception of task difficulty

1995) and 100\% (Gilmore et al., 1995; for a revision see Cocchini \& Della Sala, 2010 Table 7.2).

It seems therefore that, despite anosognosia for motor impairment is more frequently associated to a lesion (or anaesthetisation) of the right hemisphere, unawareness for right motor impairment is not a negligible phenomenon as commonly thought, though it may be less easily detectable.

The debate about hemispheric asymmetry of anosognosia may denote some contradictions possibly generated, as suggested by Baier et al. (2014), by different researcher's concept of anosognosia and consequently different selection of patients and methods, leading to investigations of potentially different underlying mechanisms (see also Morin, 2017; Jenkinson et al., 2011). The strong link between right brain damage and relatively rare severe cases of anosognosia characterised by an explicit and vehement denial of complete hemiplegia may represent a specific form of anosognosia, associated to lesions to particular brain areas (i.e., right insula - Vocat, Staub, Stroppini, \& Vuilleumier, 2010; Karnath , Baier, Nägele, 2005; Baier \& Karnath, 2008; right premotor cortex - Berti et al., 2005; wide cortical and subcortical network -Moro et al., 2016) or on the presence of associated "right brain damage deficits" (e.g., unilateral spatial neglect; Feinberg, 1997; Vocat et al., 2010; Cocchini, Beschin, \& Della Sala, 2002) that render difficult the discovery of hemiplegia for the unattended limb/s. It should be noted that $26 \%$ of our LBD patients showed some degree of personal neglect; however up to $52 \%$ of RBD patients showed the same deficit; therefore the merely presence of neglect cannot account for the hemispheric asymmetry for anosognosia.

It must, however, be considered that a growing number of studies (e.g., Ramachandran, 1995; Marcel et al., 2004; Nardone et al., 2007; Cocchini et al., 2010; Fotopoulou et al., 2010; Preston, Jenkinson, \& Newport, 2010; Moro et al., 2011; Garbarini et al., 2012; Prigatano, 2014) have demonstrated that anosognosia reveals itself in different domains and contexts, 
Cocchini et al. Unawareness and distorted perception of task difficulty

showing different clinical correlates. Therefore, the use of different, more specific methodologies may enable researchers and clinicians to identify less apparent manifestations of anosognosia, like lack of awareness in patients showing different degrees of anosognosia and anosognosia for different degrees of motor impairment.

A further observation concerns the 'similar performance' (scores) observed between anosognosic patients and healthy volunteers during the Current condition. Patients unaware of their motor impairment perceived the difficulty of the tasks similarly to healthy volunteers, as if they could still use both hands. These findings are in line with previous studies reporting a preserved motor planning in anosognosic patients, which was equivalent to healthy volunteers (e.g., Garbarini et al., 2012). Moreover, the anosognosic patients' ability to perceive the complexity of each task per se is not altered. Therefore, the anosognosic patients' ability to perceive the complexity of each task per se is not altered; however, they failed to take into account their motor impairments. This does not necessarily imply that the cause for anosognosia in all our patients can be easily traced back to a single mechanism. On the contrary, a sizable sample of 19 patients showed different performance on the two tests. Regardless of the rather speculative interpretation of single cases, it seems that lack of awareness can be caused by different reasons and the related manifestations may not be equally evident to a unique assessment method. This would be in line with the idea that anosognosia is a multifaceted syndrome (Prigatano, 2014) and may explain the relatively low, though significant, correlations between the Errand Choice Test and the VATAm. Overall suggesting that the use of a battery of tests rather than single measure of anosognosia may lead to a more detailed picture.

To conclude, evidence of anosognosia has been associated with poor rehabilitation outcome (Gialanella \& Mattioli, 1992; Maeshima et al., 1997; Hartman-Maeir et al., 2002; Appelros et al., 2002; Gialanella, Monguzzi, Santoro, \& Rocchi, 2005; di Legge, Fang, 
Cocchini et al. Unawareness and distorted perception of task difficulty

Saposnik, \& Hachinski, 2005) and increment of the risk of falls and a greater exposure to dangerous behaviours (Hartman-Maeir et al., 2001; Mograbi \& Morris, 2013; Palmer \& David, 2013; Starkstein, Jorge, Mizrahi, Adrian, \& Robinson, 2007; D’Imperio et al., 2017). These risks may be even greater for those patients who show a false awareness of their abilities by explicitly acknowledging their motor impairment but still misjudging the difficulty of bimanual tasks. These patients may possess a false sense of awareness of their own motor limitations, making them more prone to potentially risky situations. 
Cocchini et al. Unawareness and distorted perception of task difficulty

\section{Footnotes}

${ }^{1}$ For meta-analyses purposes, the clinical group partially overlaps with the groups described in Cocchini et al., 2010 and Dean et al., 2017

\section{Disclosure of interest}

The authors report no conflicts of interest.

No financial support was received for this study. 
Cocchini et al. Unawareness and distorted perception of task difficulty

\section{REFERENCES}

Albert ML. A simple test of visual neglect. Neurology 1973; 23: 658-64.

Appelros, P., Karlsson, G.M., Seiger, Å., \& Nydevik, I. (2002). Neglect and anosognosia after firstever stroke: incidence and relationship to impairment and disability. Journal of Rehabilitation Medicine, 34, 215-220.

Baier, B., \& Karnath, H-O. (2008). Tight link between our sense of limb ownership and self-awareness of actions. Stroke, 39, 486-488.

Baier, B., Vucurevic, G., Müller-Forell, W., Glassl, O., Geber, C., Dieterich, M., \& Karnath, H-O. (2014). Anosognosia for hemiparesis after left-sided stroke. Cortex, 61, 120-126.

Basso, A., Capitani, E., \& Laiacona, M. (1987). Raven's coloured progressive matrices: normative values on 305 adult normal controls. Functional Neurology, 2, 189-194.

Berti, A., Bottini, G., Gandola, M., Pia, L., Smania, N., Stracciari, A., ... Paulesu, E. (2005). Shared cortical anatomy for motor awareness and motor control. Science, 309, 488-491.

Berti, A., Làdavas, E., \& Della Corte, M. (1996). Anosognosia for hemiplegia neglect dyslexia and drawing neglect: clinical findings and theoretical considerations. Journal of International Neuropsychological Society, 2, 426-440.

Berti, A., Làdavas, E., Stracciari, A., Giannarelli, C., \& Ossola, A. (1998). Anosognosia for motor impairment and dissociations with patients' evaluation of the disorder: theoretical considerations. Cognitive Neuropsychiatry, 3, 21-44.

Beschin, N., \& Robertson, I. H. (1997). Personal versus extrapersonal neglect: A group study of their dissociation using a reliable clinical test. Cortex, 33, 379-384.

Bisiach, E., \& Geminiani, G. (1991). Anosognosia related to hemiplegia and hemianopia. In G.P.Prigatano \& D. L. Schacter (Eds.) Awareness of deficit after brain injury: Clinical and theoretical issues (pp. 17-39). New York: Oxford University Press.

Bisiach, E., Perani, D., Vallar, G., \& Berti, A. (1986). Unilateral neglect: Personal and extra-personal. Neuropsychologia, 24, 759-767.

Buchtel, H., Henry, T., \& Abou-Khalil, B. (1992). Memory for neurological deficits during the intracarotid amytal procedure: A hemispheric difference. Journal of Clinical Experimental Neuropsychology, 14, 96-97.

Carpenter, K., Berti, A., Oxbury, S., Molyneux, A.J., Bisiach, E., \& Oxbury, J.M. (1995). Awareness of and memory for arm weakness during intracarotid sodium amytal testing. Brain, 118, 243-251.

Cocchini, G., \& Della Sala, S. (2010). Assessing anosognosia for motor and language impairments. In G. Prigatano (Ed.) The study of anosognosia (pp. 123-144). NY, New York: Oxford University Press. 
Cocchini, G., Beschin, N., \& Della Sala, S. (2002). Chronic anosognosia: a case report and theoretical account. Neuropsychologia, 40, 2030-2038.

Cocchini, G., Beschin, N., \& Jehkonen, M. (2001). The Fluff test: a simple task to assess body representation neglect. Neuropsychological Rehabilitation, 11, 17-31.

Cocchini, G., Beschin, N., Cameron, A., Fotopoulou, A., \& Della Sala, S. (2009). Anosognosia for motor impairment following left-brain damage. Neuropsychology, 23, 223-230.

Cocchini, G., Beschin, N., Fotopoulou, A., \& Della Sala, S. (2010). Explicit and implicit anosognosia or upper limb motor impairment. Neuropsychologia, 48, 1489-1494.

Cocchini, G., Gregg, N., Beschin, N., Dean, M., \& Della Sala, S. (2009) VATA-L: Visual-analogue test assessing anosognosia for language impairment. The Clinical Neuropsychologist, 8, 1379-1399.

Crawford, J. R., \& Garthwaite, P. H. (2007). Comparison of a single case to a control or normative sample in neuropsychology: Development of a Bayesian approach. Cognitive Neuropsychology, 24, 343-372.

Della Sala, S., Cocchini, G., Beschin, N., \& Cameron, A. (2009). VATAm: visual-analogue test for anosognosia for motor impairment: A new test to assess awareness for motor impairment. The Clinical Neuropsychologist, 23, 406-427.

Di Legge, S., Fang, J., Saposnik, G., \& Hachinski, V. (2005). The impact of lesion side on acute stroke treatment. Neurology, 65, 81-86.

D’Imperio, D., Bulgarelli, C., Bertagnoli, S., Avesani, R., \& Moro, V. (2017). Modulating anosognosia for hemiplegia: The role of dangerous actions in emergent awareness. Cortex, 92, 187-203.

Di Rosa, E., Mapelli, D., Arcara, G., Amodio, P., Tamburin, S., \& Schiff, S. (2017). Aging and risky decision-making: New ERP evidence from the Iowa Gambling Task. Neuroscience Letters, 640, 93-98.

Durkin, M.W., Meador, K.J., Nichols, M.E., Lee, G.P., \& Loring, D.W. (1994). Anosognosia and the intracarotid amobarbital procedure (Wada Test). Neurology, 44, 978-979.

Dywan, C., McGlone, J., \& Fox, A. (1995). Do intracarotid barbiturate injections offer a way to investigate hemispheric models of anosognosia? Journal of Clinical and Experimental Neuropsychology, 17, 431-438.

Feinberg, T.E. Anosognosia and Confabulation. (1997). In: T.E. Feinberg, M. Farah (Eds.) Behavioral neurology and neuropsychology (p. 369-90). New York: McGraw-Hill.

Fotopoulou, A., Pernigo, S., Maeda, R., Rudd, A., \& Kopelman, M.A. (2010). Implicit awareness in anosognosia for hemiplegia: unconscious interference without conscious re-representation. Brain, 133, 3564-3577.

Fotopoulou, A., Rudd, A., Holmes, P., \& Kopelman, M. (2009). Self-observation reinstates motor awareness in anosognosia for hemiplegia. Neuropsychologia, 47(5), 1256-1260. 
Gainotti, G. (2005). Emotions, unconscious processes and the right hemisphere. Neuro-Psychoanalysis, 7, 71-81.

Gainotti, G., D' Erme, P., Villa, G., \& Caltagirone, C. (1986). Focal brain lesions and intelligence: a study with a new version of Raven's Colored Matrices. Journal of Clinical and Experimental Neuropsychology, 8, 37-50.

Garbarini, F., Rabuffetti, M., Piedimonte, A., Pia, L., Ferrarin, M., Frassinetti, F., ... Berti, A. (2012). 'Moving' a paralysed hand: bimanual coupling effect in patients with anosognosia for hemiplegia. Brain, 135, 1486-1497.

Garbarini, F., Piedimonte, A., Dotta, M., Pia, L., \& Berti, A. (2013). Dissociations and similarities in motor intention and motor awareness: the case of anosognosia for hemiplegia and motor neglect. Journal of Neurology, Neurosurgery, and Psychiatry, 84, 416-419.

Gialanella B, \& Mattioli F. (1992). Anosognosia and extrapersonal neglect as predictors of functional recovery following right hemisphere stroke. Neuropsychological Rehabilitation, 2, 169-178.

Gialanella, B., Monguzzi, V., Santoro, R., \& Rocchi, S. (2005). Functional recovery after hemiplegia in patients with neglect: The rehabilitative role of anosognosia. Stroke, 36, 2687-2690.

Gilmore, R.L., Heilman, K.M., Schmidt, R.P., Fennell, E.M., \& Quisling, R. (1992). Anosognosia during Wada testing. Neurology, 42, 925-927.

Grotta, J., \& Bratina, P. (1995). Subjective experiences of 24 patients dramatically recovering from stroke. Stroke, 26, 1285-1288.

Hartman-Maeir, A., Soroker, N., \& Katz, N. (2001). Anosognosia for hemiplegia in stroke rehabilitation. Neurorehabilitation and Neural Repair, 15, 213-222.

Hartman-Maeir, A., Soroker, N., Oman, S.D., \& Katz, N. (2003). Awareness of disabilities in stroke rehabilitation- A clinical trial. Disability and Rehabilitation, 7, 25, 35-44.

Hartman-Maeir, A., Soroker, N., Ring, H., \& Katz, N. (2002). Awareness of deficits in stroke rehabilitation. Journal of Rehabilitation Medicine, 34, 158-164.

Heilman, K.M. (2014). Possible mechanisms of anosognosia of hemiplegia. Cortex, 61, 30-42

Hibbard, M. R., Stein, P. S., Gordon, W. A., \& Sliwinski, M. (1992). Structured assessment of depression in brain damaged individuals (SADBD): administration and scoring manual. Mt Sinai Center, New York.

House, A., \& Hodges, J.R. (1988). Persistent denial of handicap after infarction of the right basal ganglia: A case study. Journal of Neurology, Neurosurgery, and Psychiatry, 51, 112-115.

Jenkinson, P.M., Preston, C., \& Ellis, S.J. (2011). Unawareness after stroke: A review and practical guide to understanding, assessing, and managing anosognosia for hemiplegia. Journal of Clinical and Experimental Neuropsychology, 33 (10), 1079-1093. 
Kaplan, R.F., Meadows, M.E., Cohen, R.A., Bromfield, E.B., \& Ehrenberg, B.L. (1993). Awareness of deficit after the sodium amobarbital (Wada) test. Journal of Clinical Experimental Neuropsychology, 15, 383.

Kaplan-Solms, K. L., \& Solms, M. (2000). Clinical Studies in Neuropsychoanalysis: Introduction of a Depth Neuropsychology. London: Karnac Books.

Karnath, H.O., Baier, B., \& Nägele, T. (2005). Awareness of the functioning of one's own limbs mediated by the insular cortex? Journal of Neuroscience, 25, 7134-7138.

Katz, S., Ford, A.B., Moskowitz, R.W., Jackon, B.A., \& Jaffe, M.W. (1963). Studies of illness in the aged. The index of ADL: A standardized measure of biological and psychosocial function. JAMA, $185,914-919$.

Lu, L.H., Barrett, A.M., Schwartz, R.L., Cibula, J.E., Gilmore, R.L., Uthman, B.M., \& Heilman, K.M. (1997). Anosognosia and confabulation during the Wada test. Neurology, 49, 1316-1322.

Maeshima, S., Dohi, N., Funahashi, K., Nakai, K., Itakura, T., \& Komai, N. (1997). Rehabilitation of patients with anosognosia for hemiplegia due to intracerebral haemorrhage. Brain Injury, 11, 691697.

Mahoney, F.I., \& Barthel. DW. (1965). Functional evaluation: the Barthel index. Maryland State Medical Journal, 14, 61-5.

Marcel, A., Tegnér, R., \& Nimmo-Smith, I. (2004). Anosognosia for plegia: specificity, extension, partiality and disunity of bodily unawareness. Cortex, 40, 19-40.

Marková, I.S., \& Berrios, G.E. (2014). The construction of anosognosia: history and implications. Cortex, 61, 9-17.

Mograbi, D., \& Morris, R.G. Implicit awareness in anosognosia: clinical observations, experimental evidence, and theoretical implications. (2013). Cognitive Neuroscience, 4, 181-97

Morin, A. (2007). Self-awareness and the left hemisphere: the dark side of selectively reviewing the literature. Cortex, 43, 1068-1073.

Morin, A. (2017) The "self-awareness-anosognosia" paradox explained: How can one process be associated with activation of, and damage to, opposite sides of the brain? Laterality: Asymmetries of Body, Brain and Cognition, 22: (1), 105-119.

Moro, V., Pernigo, S., Zapparoli, P., Cordioli, Z., \& Aglioti, S. M. (2011). Phenomenology and neural correlates of implicit and emergent motor awareness in patients with anosognosia for hemiplegia. Behavioural Brain Research, 225, 259-269.

Moro, V., Pernigo, S., Tsakiris, M., Avesani, R., Edelstyn, N.M.J., Jenkinson, P.M., \& Fotopoulou, A. (2016) Motor versus body awareness: Voxel-based lesion analysis in anosognosia for hemiplegia and somatoparaphrenia following right hemisphere stroke. Cortex, 83, 62-77. 
Moro, V., Scandola, M., Bulgarelli, C., Avesani, R., \& Fotopoulou, A. (2015). Error-based training and emergent awareness in anosognosia for hemiplegia. Neuropsychological Rehabilitation, 25:4, 593-616.

Nardone, I.B., Ward, R., Fotopoulou, A., \& Turnbull, O.H. (2007). Attention and Emotion in Anosognosia: Evidence of Implicit Awareness and Repression? Neurocase, 13, 438-445.

Nathanson, M., Bergman, P.S., \& Gordon, C.G. (1952). Denial of illness: Its occurrence in one hundred consecutive cases of hemiplegia. Archives of Neurology and Psychiatry, 68, 380-387.

Nurmi, M.E., \& Jehkonen, M. (2014). Assessing anosognosias after stroke: A review of the methods used and developed over the past 35 years. Cortex, 61, 43-63.

Palmer, E.C., \& David, A.S. (2013). More work on lack of awareness and insight in healthy people and psychiatric patients will assist model building. Cognitive Neuroscience, 4, 206-207.

Pazzaglia, M., Pizzamiglio, L., Pes, E., \& Aglioti, S.M. (2008). The sound of actions in apraxia. Current Biology, 18, 1766-1772.

Pia, L., Neppi-Modona, M., Ricci, R., \& Berti, A. (2004). The anatomy of anosognosia for hemiplegia: a meta-analysis. Cortex, 40: (2), 367-77.

Pia, L., Spinazzola, L., Rabuffetti, M., Ferrarin, M., Garbarini, F., Piedimonte, A., Driver, J., \& Berti, A. (2013). Temporal coupling due to illusory movements in bimanual actions; Evidence from anosognosia for hemiplegia. Cortex, 49, 1694-1703.

Piedimonte, A., Garbarini, F., Rabuffetti, M., Pia, L., Montesano, A., Ferrarin, M, \& Berti, A. (2015). Invisible grasps: Grip interference in anosognosia for hemiplegia. Neuropsychology, 29 (5), 776-781.

Preston, C., Jenkinson, P. M., \& Newport, R. (2010). Anosognosia for hemiplegia as a global deficit in motor awareness: evidence from the non-paralysed limb. Neuropsychologia, 48, 3443-3450.

Prigatano, G.P. (2014). Anosognosia and patterns of impaired self-awareness observed in clinical practice. Cortex, 61, 81-92.

Prigatano, G. P., \& Weinstein, E. A. (1996). Edwin A. Weinstein's contributions to neuropsychological rehabilitation. Neuropsychological Rehabilitation, 6, 305-326.

Ramachandran, V. S. (1995). Anosognosia in parietal lobe syndrome. Consciousness and Cognition, $4(1), 22-51$.

Ramachandran, V.S., \& Blakeslee, S. (1998). Phantoms in the Brain: The Sound of One Hand Clapping. New York: William and Co.

Ramachandran, V.S., \& Rogers-Ramachandran, D. (1996). Denial of disabilities in anosognosia. Nature, 382, 501. 
Cocchini et al. Unawareness and distorted perception of task difficulty

Spinnler, H., \& Tognoni, G. (1987). Standardizzazione e taratura italiana di test neuropsicologici. The Italian Journal of Neurological Sciences, 6 (Supplement 8).

Starkstein, S.E., Jorge, R., Mizrahi, R., Adrian, J., Robinson, R.G. (2007). Insight and danger in Alzheimer's disease. European Journal of Neurology, 14, 455-60.

Turnbull, O.H., Jones, K., \& Reed-Screen, J. (2002) Implicit awareness of deficit in anosognosia? An emotion-based account of denial of deficit. Neuropsychoanalysis, 4, 69-86.

Vocat, R., Staub, F., Stroppini, T., \& Vuilleumier, P. (2010). Anosognosia for hemiplegia: a clinicalanatomical prospective study. Brain, 133, 3578-3597.

Wade, D. T. (1992). Measurement in neurological rehabilitation. Oxford: Medical Publications.

Wilson, B. A., Cockburn, J., \& Halligan, P. (1987). Behavioural inattention test. Flempton: Thames Valley Test Company. 
Cocchini et al. Unawareness and distorted perception of task difficulty

\section{Figures captions}

Figure 1. Examples of experimental items (a) and check items (b)

Figure 2. LBD performance on the Errand Choice Test

Figure 3. RBD performance on the Errand Choice Test 
Cocchini et al. Unawareness and distorted perception of task difficulty

Figure 1. Examples of experimental items (a) and check items (b)

In your current situation, which task would be easier for you?

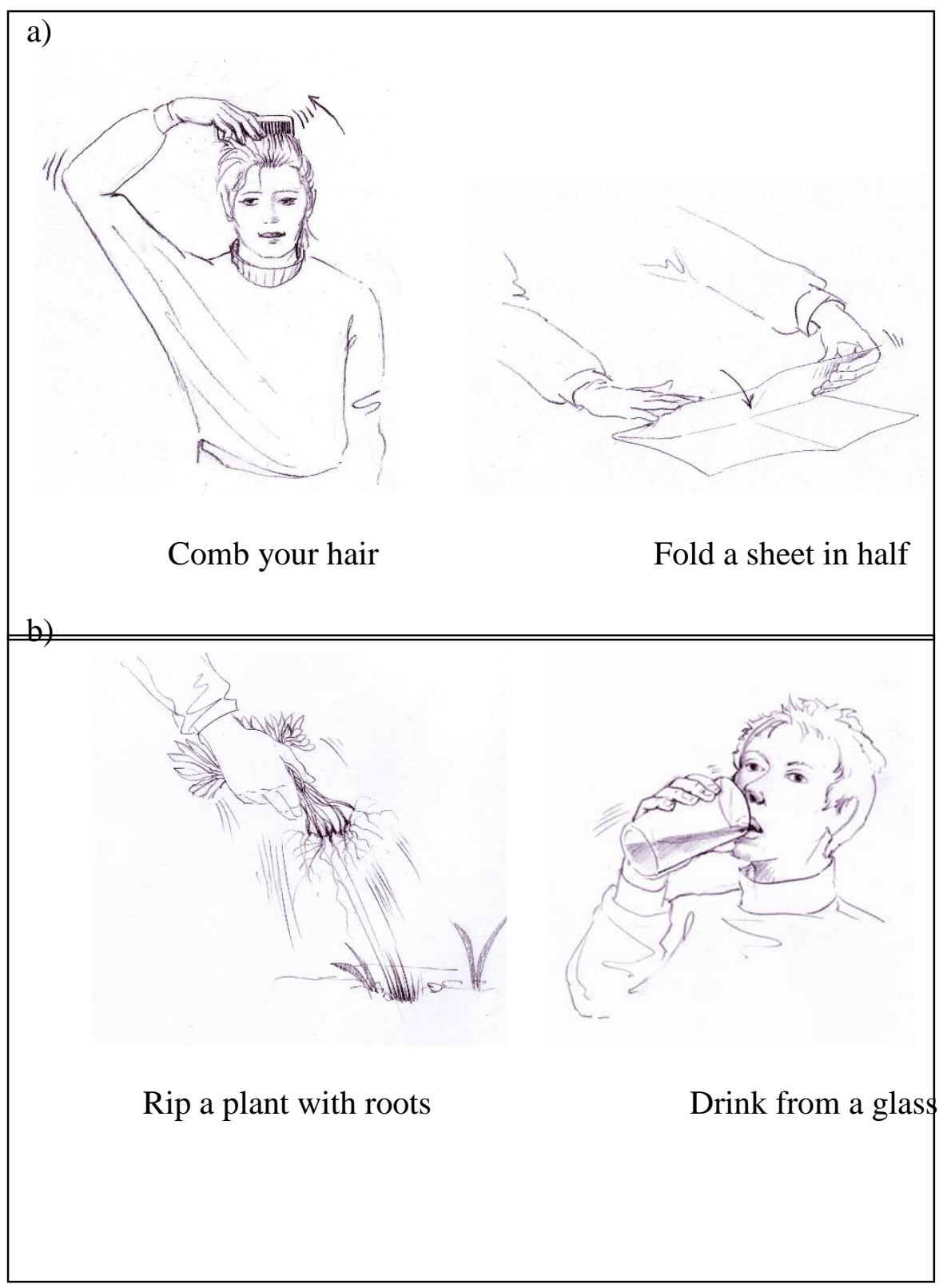


Figure 2. LBD performance on the Choice Task Test.

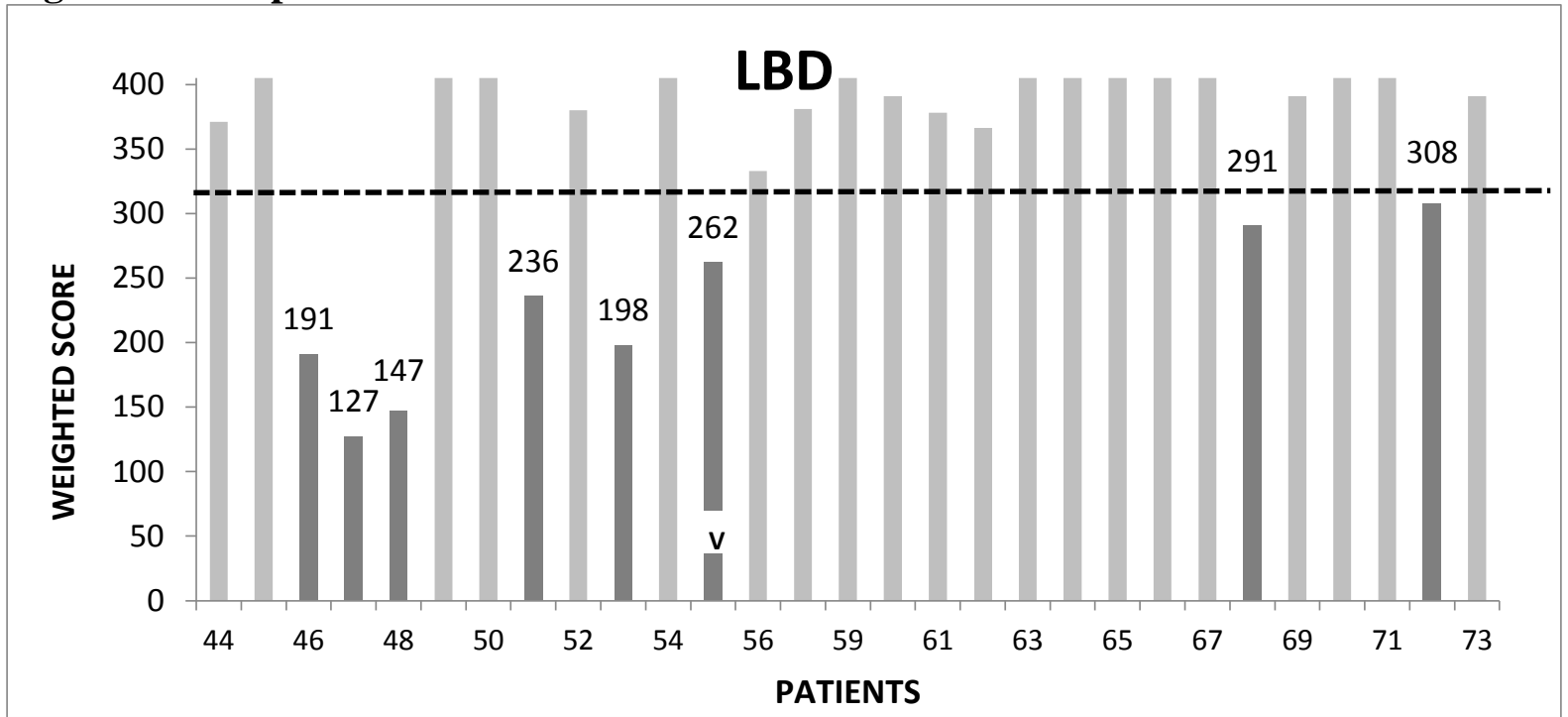

Dashed line indicates cut-off. Darker bars indicate pathological performance with score reported.

Patient 57 was excluded for failing check questions.

V: Patient performing below cut-off on the Errand Choice Test who did not show lack of awareness (i.e. score $=-7.5$ ) on the $\operatorname{VATAm}(\mathrm{V})$.

Figure 3. RBD performance on the Choice Task Test.

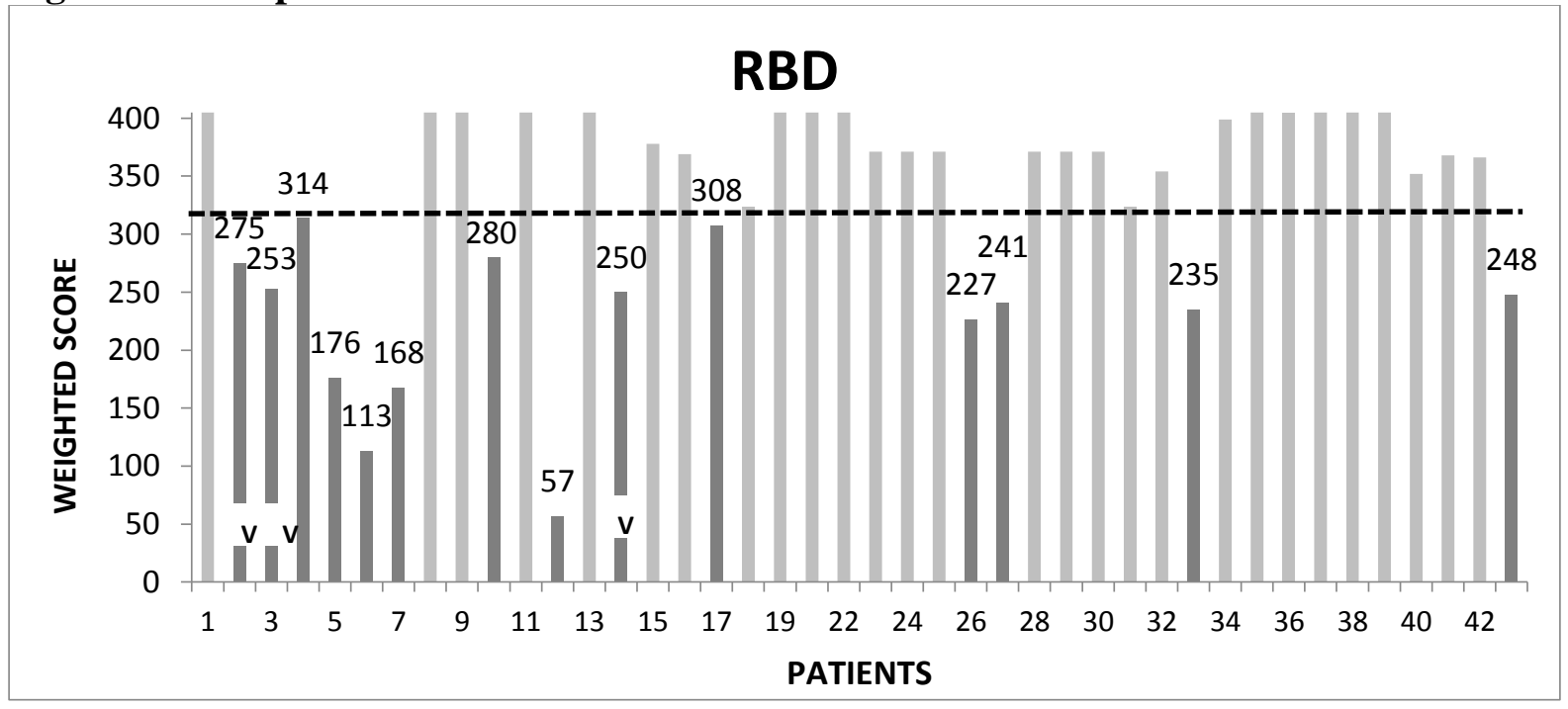

Dashed line indicates cut-off. Darker bars indicate pathological performance with score reported.

Patient 20 was excluded for failing check questions.

V: Patient performing below cut-off on the Errand Choice Test who did not show lack of awareness on the VATAm (V). Patients: 2, 3 and 14 obtained a score of $-2,1$ and 0 , respectively. 
Cocchini et al. Unawareness and distorted perception of task difficulty

Table 1. Methods assessing less overt aspects of anosognosia for motor impairment

References

Brief description of assessment

Observational evidence

Prigatano \& Weinstein, 1996; Gialanella \& Mattioli, 1992; Ramachandran \& Blakeslee, 1998; Berti et al., 1998;

Gainotti, 2005; Fotopoulou et al., 2009; Cocchini et al., 2010;

Turnbull et al., 2014; Prigatano, 2014

Kaplan-Solms \& Solms, 2000

\section{Experimental evidence}

House \& Hodges, 1988

Ramachandran, 1995

Ramachanrdan \& Rogers-Ramachandran, 1996

Ramachandran \& Blakeslee, 1998; Hartman-Maeir et al., 2001

Ranchandran \& Blakeslee, 1998; Cocchini et al., 2002

Hartman-Maeir et al, 2001

Turnbull et al., 2002

Marcel et al., 2004 (see also Berti et al., 1996)

Nardone et al., 2007

Cocchini et al., 2010

Fotopoulou et al., 2010

Moro et al., 2011

Garbarini et al., 2012

Garbarini et al., 2013

Pia et al., 2013

Piedimonte et al., 2015

Moro et al., 2015

DTmperio et al., 2017

Inferred from information collected during a context of psychoanalytic psychotherapy.

Patient identified pictures of people in wheelchair as more alike to her

Inferred from patients' behaviour/comments - e.g., "tacit knowledge of her [patient's] physical condition was apparent in most conversations" (Berti et al 1998; p. 21"); "In my mind's eye you can see that you [the patient] are lifting your hand. But you [the examiner] can't see that" (Tumbull et al, 2014).

Choice of uni-manual or bi-manual tasks. Choice of bi-manual tasks indicated lack of implicit awareness. Virtual-box was used to provide illusory movement of hemiplegic limb.

Inferred from patient's acknowledgment of motor deficit in other persons

Inferred from patient's behaviour on bi-maunal task.

Inferred from patient's comments following a procedure to induce "illusory paralysis of arm".

Choice of uni-manual or bi-manual tasks. Choice of bi-manual tasks indicated lack of implicit awareness.

Emotional valence observed in patients' free association tasks and behaviours indicated implicit awareness.

1st-3rd Person Estimates Test. Patients were asked to rate motor ability of examiner had he been in their current situation. Acknowledge of "examiner's" difficuty to perform bi-manual or bi-pedal-tasks was considered evidence of implicit awareness.

Reaction times on decision task. Increment of RTs, when a distractor related to motor activities was displayed, indicated evidence of implicit awareness.

Patients' behaviour on bi-manual tasks. Uni-manual strategies to approach bimaunal tasks was considered as evidence of implicit awareness.

Patients asked to complete sentences from modified Halyley test. Increment of latencies when sentence contains motor related information was considered as evidence of implicit awareness.

Patients grasped heavy objects with their unaffected hand. Grip towards the centre was considered as evidence of implicit awareness.

Anosognosic patients were asked to simultaneously trace out lines with their unaffected hand and circles with their paralysed hand. Bimanual coupling effect on the trajectories of the intact hand (i.e., lines tending to assume an oval trajectory) was considered as evidence of intact intention to move of anosognosic patients.

Patients grasp/pretend to grasp objects with their unaffected hand. Uni-manual strategies to approach bi-manual tasks is considered as evidence of implicit awareness.

Patients were asked to reach one or two targets using one (unimanual) or both (bimanual) arms. Usually, the reaching time of one hand increases during the bimanual tasks (temporal coupling effect). This effect was not present in patients aware of their hemiplegia. However, anosognosic patients showed a temporal coupling effect equivalent to that observed in healthy volunteers. These findings suggest that in anosongosic patients, the illusory movements of the plegic limb can impose a motor contraint on the intact limb.

Patients were asked to reach and grasp with one or both hands wooden cilinders of different sizes. Maximum grip aperture of the intact hand was recorded. In patients with anosognosia, the grip aperture of the intact han was influenced by the intended (though not executed) movement of the plegic hand; whereas patients aware of their hemiplegia did not show any interference effect between plegic and intact hand.

Patients were first asked to declare whether they were able to perform specific actions with their ipsilesional or contralesional hand. After verbal response, they were asked to attempt to execute each action using any suitable strategy Finally, they were asked to analyse their own strategies, errors and discuss possible reasons for failures.

Patients were asked to attempt actions that were either impossible for hemiplegic persons or potentially dangerous. Emergent awareness (i.e. verbal report of the motor deficit) increased significantly following attempted execution of these tasks. 
Cocchini et al. Unawareness and distorted perception of task difficulty

Table 2. Demographic and clinical features of LBD and RBD patients entering the study. Means, standard deviations (in parentheses) and range are shown.

\begin{tabular}{|c|c|c|c|c|c|c|c|c|c|}
\hline & \multirow[b]{2}{*}{ Age } & \multirow{2}{*}{$\begin{array}{l}\text { Years of formal } \\
\text { education }\end{array}$} & \multirow[b]{2}{*}{ Gender } & \multirow[b]{2}{*}{ Days from onset } & \multicolumn{3}{|c|}{ Locus of lesion } & \multirow{2}{*}{$\begin{array}{c}\text { Motricity Index } \\
\text { (Upper limb) } \\
(1-100)\end{array}$} & \multirow{2}{*}{$\begin{array}{l}\text { ADL } \\
(0-20)\end{array}$} \\
\hline & & & & & $\begin{array}{c}\text { Encompassing } \\
\text { F-P }\end{array}$ & $\begin{array}{l}\text { Limited to } \\
F \text { or } P\end{array}$ & \begin{tabular}{c|} 
Limited to \\
subcortical \\
structures
\end{tabular} & & \\
\hline LBD & $64.8(12.4) 40-85$ & $8.4(4.4) 2-17$ & $16 \mathrm{~F} ; 14 \mathrm{M}$ & 101.6 (49.8) $10-149$ & 26 & 3,0 & 1 & $14.0(26.0) 1-77$ & $8.5(3.5) 2-14$ \\
\hline RBD & $62.0(13.8) 29-84$ & $9.2(4.3) 4-18$ & $17 \mathrm{~F} ; 26 \mathrm{M}$ & $77.2(60.8) 10-199$ & 21 & 1,5 & 16 & $23.4(25.1) 1-58$ & $8.6(4.5) 0-14$ \\
\hline ALL & $63.2(13.2) 29-85$ & $8.9(4.3) 2-18$ & $33 \mathrm{~F} ; 40 \mathrm{M}$ & $87.2(57.4) 10-199$ & 47 & 4,5 & 17 & $19.6(25.7) 1-77$ & $8.5(4.1) 0-14$ \\
\hline
\end{tabular}

$\mathrm{ADL}=$ Activity of Daily Life (Katz et al., 1963)

F-P: number of patients with a lesion enchroaching upon the frontal $(F)$ and the parietal $(P)$ lobes

$F$ or $P$ : number of patients with a lesion LIMITED to the frontal $(F)$ or the parietal $(P)$ lobes.

Table 3. Percentages of patients showing pathological performance on tasks assessing contralesional neglect, reasoning abilities and memory processing

\section{Extrapersonal neglect}

Personal Neglect

$26 \%(13 \%-10 \%-3 \%)$

$52 \%(26 \%-19 \%-7 \%)$

RBD
$33 \%(7 \%-13 \%-13 \%)$

$(9 \%-5 \%-26 \%$

\section{Reasoning}

$20 \%$

$33 \%$
Short-term memory

$0 \%$

$19 \%$

In brackets, percentages of patients showing evidence of neglect on one, two or all three tests 
Table 4. Percentages of uni-manual choices made by the controls in the Current and Simulated conditions.

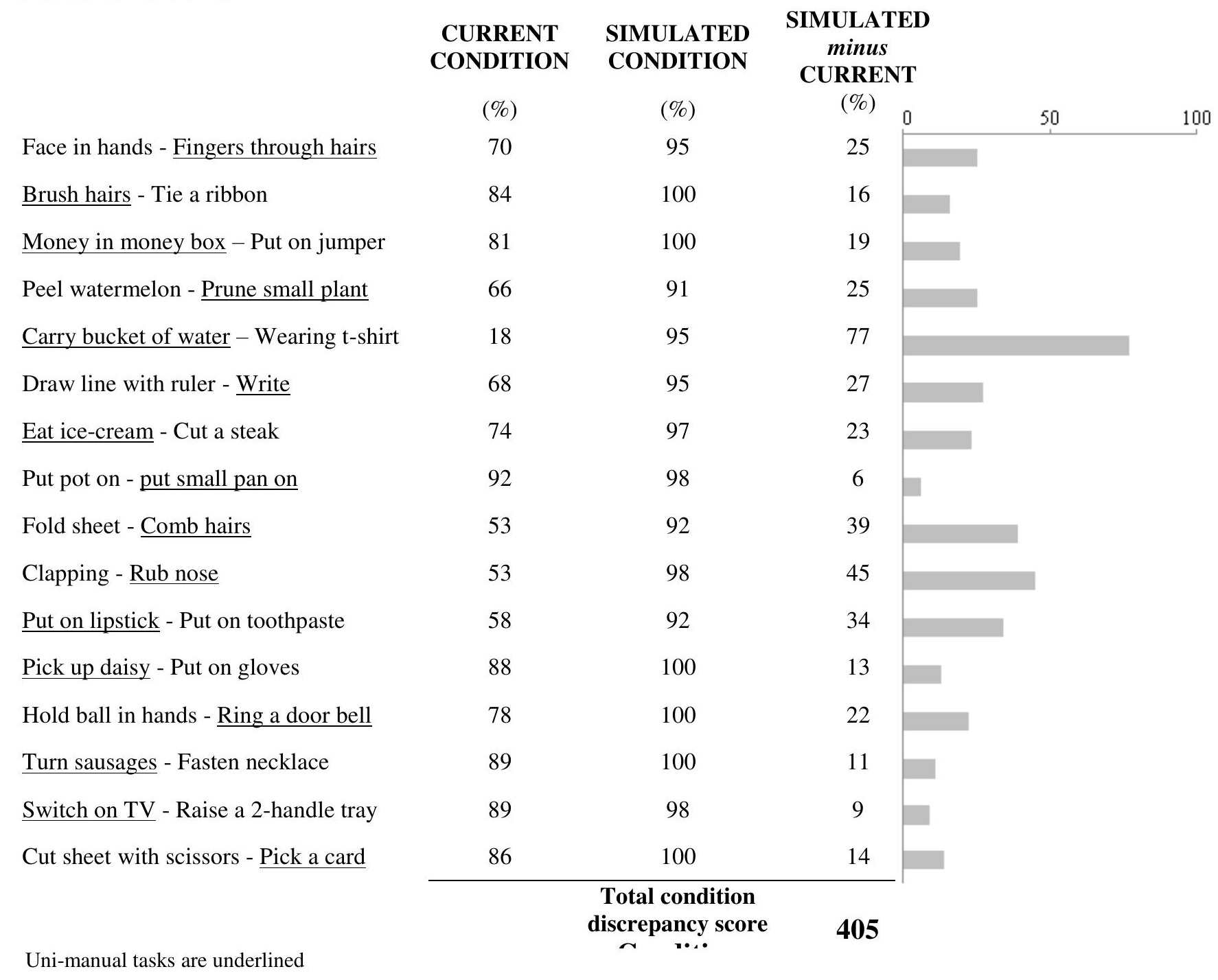


Table 5. Average (sd) of VATAm and ECT scores for aware and unaware patients

\begin{tabular}{lcccc} 
& & AWARE & UNAWARE & TOTAL \\
\cline { 3 - 5 } $\begin{array}{c}\text { VATAm } \\
\text { (discrepancy score) }\end{array}$ & LBD & $-1.9(3.6)^{*}$ & $16.1(6.2)$ & $6.5(10.4)$ \\
& RBD & $-0.7(2.3)^{*}$ & $14.7(7.1)$ & $6.8(9.3)$ \\
ECT & LBD & $392.5(18.8)$ & $220.0(65.6)$ & $344.9(86.5)$ \\
$\begin{array}{c}\text { (unilateral score) } \\
\text { RBD }\end{array}$ & $383.0(25.0)$ & $224.6(72.9)$ & $330.2(88.4)$ \\
& & & & \\
\# Note that negative scores indicates patients' overestimation of their motor \\
impairment compared to caregivers' rating
\end{tabular}

Table 6. Number of patients showing lack of awareness on the VATAm and ECT

\begin{tabular}{l|ccc|c} 
& VATAm ONLY & ECT ONLY & VATAm + ECT & TOT unaware \\
29 LBD & 6 & 1 & 7 & $14(48 \%)$ \\
42 RBD & 9 & 3 & 11 & $23(55 \%)$ \\
\hline 71 TOT & $15(21 \%)$ & $4(6 \%)$ & $18(25 \%)$ & $37(52 \%)$
\end{tabular}

